\section{Current approaches to pediatric heart catheterizations}

\author{
Philip A. Bernard,1 Hubert Ballard,2 \\ Douglas Schneider ${ }^{3}$
}

1Department of Pediatrics, Heinrich A. Werner Division of Pediatric Critical Care; 2Department of Pediatrics, Division of Neonatology; 3Department of Pediatrics, Division of Cardiology, Kentucky Children's Hospital, University of Kentucky, USA

\section{Abstract}

Sedation for pediatric cardiac catheterization is a common requirement in many institutions. As the field of cardiac catheterization has evolved, the provision of sedation for these procedures has been varied. Increasingly the demand is for dedicated personnel focused on monitoring and delivery of sedation while in the catheterization suite. This article describes the considerations one must use when undertaking these cases.

\section{Introduction}

Modern pediatric cardiac catheterization began with in 1947 when Bing described using catheterization for diagnosis of congenital heart disease. In the ensuing period, echocardiography has become increasing refined and has supplanted the need for many diagnostic catheterizations. However, interventional catheterizations have increasingly become a mainstay of pediatric care. Pediatric interventional catheterization began in earnest in 1968 with balloon atrial septostomyl and quickly became a common procedure in pediatric catheterization. Numerous advances occurred in the 1980s and 1990s. Modern pediatric cardiac catheterization can now treat a number of conditions including patent ductus arteriosus, atrial septal defects, ventricular septal defects, collateral vessels, valve stenosis, vessel stenosis, and conduction abnormalities. Increasing minimally-invasive procedures has strained the traditional model of anesthesia-directed care in the operating room environment with a variety of providers now administering analgesia and sedation for children.2 Pediatric heart catheterizations have increased exponentially in recent years. ${ }^{3}$ Sedation has traditionally been under the direction of the performing cardiologist. However, the need to have the patient be motionless has increased as the number of interventions has increased. In addition, there is increased recognition that dedicated personnel focused on monitoring of the patient during sedation are associated with improved safety. As the demand for sedation outside of the operating room has increased, a number of providers have gained experience in providing for the sedation and analgesia of these patients. In addition to a number of different provider models, wide variations exist in approaches to sedation regimens. ${ }^{4}$ The different types of practitioners as well as the special circumstances that accompany congenital heart disease require special emphasis.

\section{Composition of sedation team}

A striking variety of practice models exist in pediatric catheterization suites. Depending on the practice setting, pediatric cardiologists, registered nurses, Certified Registered Nurse Anesthetist's (CRNA), anesthesiologists, hospitalists, pediatric emergency physicians, and pediatric intensivists may perform the primary role of sedation. Regardless of the provider, it is essential that safe and effective sedation be practiced. Debate continues for and against non-anesthesiologists performing these sedations. ${ }^{5-7}$ Regardless of the team composition, consistency in NPO guidelines, monitoring, and ability for resuscitation must be kept. The reader is referred to excellent general guidelines available through the 2006 American Academy of Pediatric Sedation Guidelines and the 2002 American Society for Anesthesiologists Practice Guidelines for Sedation and Analgesia by Non-Anesthesiologists. ${ }^{8,9}$

\section{Pre-procedural considerations}

Prior to sedation, adequate consideration of a patient's physiologic status must be undertaken. Important features include underlying physiology, comorbidities and procedure to be performed. Some cooperative patients (older children and adults with congenital heart disease) may be able to have anxiolysis or light sedation and achieve excellent outcomes. Younger children will however require deep sedation (minimal response to painful stimuli) at least initially. The goals of catheterization must be reviewed (Table 1).

\section{Congenital heart disease}

Patients with congenital heart lesions are a common group of children undergoing pediatric cardiac catheterization. Understanding of the specific lesion and how hypotension, hypoor hypercarbia, and supplemental oxygen alter the patient's hemodynamics is critical. Volume status changes and afterload alterations can severely alter the physiology of both cyanotic and acyanotic lesions.

Included in the preoperative checklist is a review of the latest echocardiogram, hospital history, and previous surgical procedures.

The authors strongly recommend that seda-
Correspondence: Philip A. Bernard, University of Kentucky, Department of Pediatrics, 800 Rose Street, MN-464A, Lexington, KY 40536, USA. Tel: +1.859.323.1496 - Fax: +1.859.257-6066. E-mail: philip.bernard@uky.edu

Key words: sedation, pediatric cardiac catheterization, congenital heart disease, propofol, dexmedetomidine, ketamine, etomidate, midazolam.

Received for publication: 26 May 2011

Revision received: 4 August 2011.

Accepted for publication: 4 August 2011.

This work is licensed under a Creative Commons Attribution NonCommercial 3.0 License (CC BYNC 3.0).

(C) Copyright P.A. Bernard et al., 2011

Licensee PAGEPress, Italy

Pediatric Reports 2011; 3:e23

doi:10.4081/pr.2011.e23

tion is undertaken only by practitioners intimately familiar with the cardiovascular physiology of these conditions. Choices such as supplemental oxygen, assisted or mechanical ventilation changes in acid-base status, and alterations of systemic and pulmonary vascular resistance will alter interpretation of diagnostic data.

\section{Interventional catheterization}

Interventional catheterizations require special consideration. The technical nature of these procedures demands minimal spontaneous movement. Many interventions are more painful (e.g. aortic angioplasty) than a diagnostic catheterization; requiring substantially more attention to analgesic needs. In addition, closure devices for atrial septal defects and ventricular septal defects alter the hemodynamics of the patient. Relatively high complication rates are associated with closure devices that alter sedation management.10,11 The practitioner must be able to rapidly address cardiorespiratory changes in these patients. As with all deep sedations, expertise in airway management and intubation is a must. 12

\section{Radiofrequency ablation}

The need for sedation has increased as techniques for radiofrequency ablation have advanced. Many of these children have congenital heart disease, in addition to managing the arrhythmia-induced cardiovascular changes that are prerequisite with these patients. These patients also have longer procedure times than other candidates for procedural sedation. Joung et al found that their procedure times for atrial tachycardias averaged $131.0 \pm 48.8$ minutes. However, they also found that the procedure time was reduced 
when the patient received sedation rather than general anesthesia. ${ }^{13}$ Concerns that the sedation or anesthesia regimen may alter the conduction pathways and invalidate the electrophysiology study may be exaggerated. ${ }^{14,15}$

\section{Goals of catheterization}

As with any procedure, the sedation technique will vary depending on the goal of the procedure. For instance, in a diagnostic catheterization to determine the degree of reversible pulmonary vascular disease, multiple variables would need to be considered. Hypo- or hyperventilation, supplemental oxygen, and acid-base status need to be manipulated. Therapeutic agents that alter vascular tone will ultimately alter the interpretation of the study. 16 The prodecuralists must communicate their interventions with particular attention paid to the ramifications on the patient's hemodynamics.

\section{Sedation regimens}

The ideal sedative agent does not exist.

\section{Demerol, Phenergan and Thorazine}

Traditionally, agents such as Demerol, Phenergan, and Thorazine (DPT) have been used in pediatric catheterizations. Benefits of its use included oral or intramuscular administration. However, variable efficacy and a marked complication and side effect profile have been documented. Other oral agents have been documented to have superior efficacy to DPT. 17 In 2005, the American Academy of Pediatrics retired its policy on DPT and instead wrote Neither the combination itself nor its dosage is based on sound pharmacologic data. There is a high rate of therapeutic failure as well as a high rate of serious adverse reactions, including respiratory depression and death, associated with its use. Even when it is effective, DPT appears to lack many of the desirable characteristics of a sedative for children.

While many practitioners may have experience and expertise using this combination of medications, this regimen is likely to have greater complications and adverse effects than other regimens. In 2004, a black box warning was added to promethazine contraindicating its use in children under 2 years of age secondary to the severe adverse-events, including death. Most practitioners have discontinued this practice.

\section{Midazolam}

Midazolam is a short-acting benzodiazepine with a large body of evidence in pediatric care. Among the reason for midazolam's popularity is its ability to be given through a variety of routes, including nasal administration. Commercially, it is the most commonly used pediatric premedication for generalized anesthesia. ${ }^{18}$ In the anesthetic setting, premedication with midazolam has no significant car-

Table 1. Goals of catheterization.

1. Analgesia, anxiolysis, and amnesia for patient

2. Easy separation from parents at start of case

3. Maintain airway and appropriate ventilation

4. Monitor and maintain appropriate acid-base status

5. Minimize cardiovascular stress on the patient

6. Optimize hemodynamic status before, during, and after the procedure, tailored to the specific physiology of the individual patient

7. Immobilization for precision, particularly when interventions are needed

8. Smooth transition to awake state after procedure, minimizing cardiovascular stress upon awakening (avoiding/minimizing agitation, hypertension, coughing fits, tachycardia, etc)

9. Provide appropriate conditions for obtaining useful cath data (i.e. testing with nitric oxide, valsalva, spontaneous breathing vs positive pressure ventilation, etc)

diorespiratory effects. ${ }^{19}$ While an effective anxiolytic in most children, a significant minority of children have extreme distress nonetheless. ${ }^{20}$

Midazolam has been successfully used as a solo agent for pediatric catheterization. Jobier et al. describe a cohort of 35 patients within a group of 154 patients who received midazolam $0.14 \mathrm{mg} / \mathrm{kg} / \mathrm{hr}$ intravenously without complications. ${ }^{21}$ Unfortunately in this study, there was no criteria as to what criteria supported the used of midazolam as an only agent.

\section{Ketamine}

Ketamine is a hypnotic/sedative medication preferred by many in pediatric catheterization suites. ${ }^{22}$ Among its benefits is the ability to protect airway reflexes with minimal effect on respiration with preserved cardiac function. Concerns regarding emergence reactions have limited its usage. However, in a study by Karapinar et al., emergence reactions occurred in less than $2 \%$. Some clinicians co-administer midazolam to prevent these reactions; however, the efficacy of this practice has been debated. ${ }^{23}$

Although some tout ketamine as having minimal hemodynamic effect, ketamine can significantly alter catheterization data. ${ }^{22}$ Ketamine preserves cardiac function through increased sympathetic effects. Whether ketamine increases pulmonary vascular resistance remains to be elucidated. ${ }^{24}$ Some have seen increases in systemic vascular resistance also. For instance, ketamine is frequently used with lesions such as aortic stenosis in which excessive afterload reduction may be deleterious. Other sedation regimens may be better suited for other lesions, which cannot tolerate increases in afterload, such as mitral regurgitation.

\section{Propofol}

The commercial availability of propofol in 1989 brought the ability to induce general anesthesia outside of the confines of the operating room. Expensive inhaled anesthesia machines and scavenger devices introduced the concept of safari teams. ${ }^{25}$ In addition, nonanesthesiologists became increasingly comfortable with this medication and propofol services were introduced. 26

It is important to note there are currently three preparations of propofol approved for use by the FDA. One of these preparations uses benzyl alcohol as its emulsion agent. Infants have had significant toxicity and even death as a result of high doses given as a preservative.

Propofol has a number of properties that make it advantageous over other sedation regimens. It has many, but not all, of the properties of an ideal sedative drug. It has a predictable onset of action, a short half-life with a rapid recovery time, and is easily titratable. However, propofol is associated with profound respiratory depression outside of a fairly narrow therapeutic window. Like all of the sedative regimens listed here, propofol provides no analgesic activity. In fact, there is some evidence that propofol given in sub-anesthetic doses induces hyperalgesia. ${ }^{27}$ In addition, propofol induces clinically relevant changes in cardiac index with decreases in afterload and preload. 28

Prolonged propofol sedation should not occur in children. In 2001, the FDA issued a black box warning which reported the results of a study of 327 sedated patients in pediatric intensive care units treated with either propofol or standard sedative agents. In this unpublished study, a significantly higher number of patients died in the propofol arms of the study. Many speculate that the increased incidence of mortality may be due to propofol infusion syndrome. The syndrome, characterized by a profound metabolic acidosis, rhabdomyolysis, and ensuing death was first described in children. ${ }^{29}$ The mechanism of action, thought to be mitochondrial poisoning, has yet to be elicited. In adults, recent reports show that even short-term administration of propofol can cause a metabolic acidosis. ${ }^{30}$ These findings are also present in children undergoing cardiac catheterization (unpublished data Turner). Some believe this acidosis may be an early indication of propofol infusion syn- 
drome. 31

In the setting of pediatric catheterization, propofol (usually in combination with an analgesic) has been used with increasing frequency. In practice, PVR remains constant; while SVR decreases. ${ }^{32}$ Diagnostic data needs to be interpreted with this in mind as this does decrease shunt ratios. In addition to patients with cardiomyopathies, congenital cyanotic heart lesions may be particularly susceptible to deterioration. 33

\section{Propofol and ketamine}

In an effort to preserve SVR while retaining the positive aspects of propofol (quick onset of action, predictable response, rapid recovery time), some practices have incorporated the addition of ketamine infusions. 34,35 Ketamine and propofol have opposing influences on blood pressure, heart rate, and SVR. In addition, ketamine supplementing a propofol infusion has been shown to preserve respiratory function and upper airway control in several studies. 34,36 Recovery times were 20 minutes in a group of children given propofol at 25 $\mathrm{ug} / \mathrm{kg} / \mathrm{min}$ with the addition of ketamine at $12.5 \mathrm{ug} / \mathrm{kg} / \mathrm{minute} .^{34}$

\section{Dexmedetomidine}

Dexmedetomidine is a $\alpha_{2}$ agonist sedative and mild analgesic approved by the FDA in 1999 which preserves cardiorespiratory function. It has similar actions to clonidine, another $\alpha_{2}$ agonist. However, dexmedetomidine has a short half-life elimination of 6 minutes and terminal half-life of 2 hours. Although approved for mechanically ventilated adults for periods less than 24 hours, experience is increasing in using this medication in children. Over 2300 sedations have been reported to the pediatric sedation research consortium (Berkenbosch - unpublished data).

Munro et al sedated 20 children for cardiac catheterization with dexmedetomidine. 37 Patients were given $1 \mathrm{ug} / \mathrm{kg}$ loading dose over 10 minutes followed by an infusion of 1 $\mathrm{ug} / \mathrm{kg} / \mathrm{hr}$. Of these 20 patients, 12 patients required a bolus of propofol for movement, increasing BIS values, or prior to stimulation. The patients had stable hemodynamics throughout.

Tosun et al. compared the combination of dexmedetomidine-ketamine to propofol-ketamine in 44 patients. 38 Two regimens were compared:

1. dexmedetomidine $0.7 \mathrm{ug} / \mathrm{kg}$ loading dose over 10 minutes followed by an infusion of 1 $\mathrm{ug} / \mathrm{kg} / \mathrm{hr}$ and ketamine $1 \mathrm{mg} / \mathrm{kg}$ bolus with 1 $\mathrm{mg} / \mathrm{kg} / \mathrm{hr}$ infusion

2. propofol $1 \mathrm{mg} / \mathrm{kg}$ bolus followed by an infusion of $100 \mathrm{ug} / \mathrm{kg} / \mathrm{min}$ and ketamine $1 \mathrm{mg}$ $/ \mathrm{kg}$ bolus with $1 \mathrm{mg} / \mathrm{kg} / \mathrm{hr}$ infusion

In the Tosun study, patients on the dexmedetomidine regimen required more sup- plemental doses of ketamine for discomfort. No differences in side effects were noted, including hypotension. In addition, recovery times were significantly longer (45 v. 20 minutes; $\mathrm{P}=0.01$ )

To date, no studies have been performed which examine the effects of dexmedetomidine alone or in combination with other sedatives on pediatric catheterization data including SVR and shunt ratios.

\section{Etomidate}

Etomidate is another medication, which has recently fallen out of favor. Documentation of adrenal axis suppression as well as painful induction has decreased its usage in intensive care settings. However, in some institutions, its favorable hemodynamic profile has made it a common medication among children with reserved hemodynamic function. Sarkar et al. examined the hemodynamic responses to 12 children undergoing pediatric cardiac catheterization for ablation of superventricular tachycarida or ASD closure. There were no significant changes in hemodynamic profiles in these children. ${ }^{39}$

\section{Analgesics}

Control of pain is an essential component to a well-performed sedation. The provision of sedative agents does not provide for pain relief. Some agents (e.g. propofol) have hypergesic properties. This must be tempered with the realization that the addition of opioid agents may act synergistically other sedative agents. Topical agents such as EMLA and LMX4 as well as subcutaneous local anesthetics can dramatically decrease the need for systemic agents. Many our patients require minimal sedation following administration of local lidocaine and catheter insertion. Some older patients may tolerate a catheterization with minimal sedation if their pain needs are cared for.

\section{Special considerations}

Regardless of the sedation regimen implemented, pediatric cardiac patients have unique characteristics that need to be acknowledged. For example, the addition of supplemental oxygen can dramatically alter cardiac output, as well as alter the interpretation of catheterization data. Alterations in ventilation with positive pressure, hypo- or hyperventilation may alter pulmonary blood flow, again leading to data that may be difficult to interpret

Consideration must be taken into the length of the procedure. Recent reports highlight the potential deleterious effects of sedatives such as ketamine, propofol, and midazolam on the developing brain. ${ }^{40,41}$ As the length of the procedure increases, attention to metabolic substrates (i.e. glucose), environmental stresses, temperature regulation, and pulmonary toilet must be addressed. Coordination of the sedation procedurals with the cardiologist is a must to ensuring optimal outcomes.

Post-sedation care is a continuation of the procedure. Qualified personnel, trained in resuscitation from deep sedation and general anesthesia, as well as knowledgeable of congenital heart defects, should monitor these patients until ready for ultimate disposition.

\section{Conclusions}

Advances in pediatric catheterization have increased the demand and complexity of patients undergoing these procedures. This patient population presents unique challenges due to the large variability of their underlying anatomy and physiology. Sedation regimens are varied, with importance to the hemodynamic profile of the patients. Dedicated sedation teams are a necessary requirement to optimal performing catheterization labs.

\section{References}

1. Rashkind WJ, Miller WW. Transposition of the great arteries. Results of palliation by balloon atrioseptostomy in thirty-one infants. Circulation 1968;38:453-62.

2. Cravero JP, Blike GT, Beach M, et al. Incidence and nature of adverse events during pediatric sedation/anesthesia for procedures outside the operating room: Report from the Pediatric Sedation Research Consortium. Pediatrics 2006; 118:1087-96.

3. Allen HD, Beekman RH III, Garson A Jr, et al. Pediatric therapeutic cardiac catheterization: A statement for healthcare professionals from the council on cardiovascular disease in the young, American Heart Association. Circulation 1998;97:609-25.

4. Cravero JP, Blike GT. Review of pediatric sedation. Anesth Analg 2004;99:1355-64.

5. Verghese ST, Martin GR. Heavy sedation versus general anesthesia for pediatric invasive cardiology: a Grayer shade of blue versus a pinker shade of pale? Pediatr Cardiol 2003;24:193-4.

6. Andropoulos DB, Stayer SA. An anesthesiologist for all pediatric cardiac catheterizations: luxury or necessity? J Cardiothorac Vasc Anesth 2003;17:683-5.

7. Motas D, McDermott NB, VanSickle T, et al. Depth of consciousness and deep sedation attained in children as administered by nonanaesthesiologists in a children's hospital. Paediatr Anaesth 2004;14:256-60.

8. American Academy of Pediatrics, 
American Academy of Pediatric Dentistry, Cote CJ, et al. Guidelines for monitoring and management of pediatric patients during and after sedation for diagnostic and therapeutic procedures: An update. Pediatrics 2006;118:2587-02.

9. Practice guidelines for sedation and analgesia by non-anesthesiologists. Anesthesiology 2002;96:1004-17.

10. Hickey PR, Wessel DL, Streitz SL, et al. Transcatheter closure of atrial septal defects: hemodynamic complications and anesthetic management. Anesth Analg 1992;74:44-50.

11. Laussen PC, Hansen DD, Perry SB, et al. Transcatheter closure of ventricular septal defects: hemodynamic instability and anesthetic management. Anesth Analg 1995;80:1076-82.

12. Motas D, McDermott NB, VanSickle T, et al. Depth of consciousness and deep sedation attained in children as administered by nonanaesthesiologists in a children's hospital. Pediatric Anesthesia 2004;14: 256-60.

13. Boyoung Joung ML, Jung-Hoon Sung, Jong-Youn Kim, et al. Pediatric radiofrequency catheter ablation. Circ J 2006;70: 278-84.

14. Lavoie J, Walsh EP, Burrows FA, et al. Effects of propofol or isoflurane anesthesia on cardiac conduction in children undergoing radiofrequency catheter ablation for tachydysrhythmias. Anesthesiology 1995;82:884-7.

15. Lai LP, Lin JL, Wu MH, et al. Usefulness of intravenous propofol anesthesia for radiofrequency catheter ablation in patients with tachyarrhythmias: infeasibility for pediatric patients with ectopic atrial tachycardia. Pacing Clin Electrophysiol 1999:22:1358-64.

16. Fixler DE, Carrell T, Browne R, et al. Oxygen consumption in infants and children during cardiac catheterization under different sedation regimens. Circulation 1974;50:788-94.

17. Auden SM, Sobczyk WL, Solinger RE, et al. Oral Ketamine/Midazolam is superior to intramuscular Meperidine, Promethazine, and Chlorpromazine for pediatric cardiac catheterization. Anesth Analg 2000;90:299305 .

18. Annila P, Rorarius M, Reinikainen P, et al. Effect of pre-treatment with intravenous atropine or glycopyrrolate on cardiac arrhythmias during halothane anaesthesia for adenoidectomy in children. Br $\mathrm{J}$
Anaesth 1998;80:756-60.

19. Audenaert SM, Wagner Y, Montgomery CL, et al. Cardiorespiratory effects of premedication for children. Anesth Analg 1995;80:506-10.

20. Kain ZN, MacLaren J, McClain BC, et al. Effects of age and emotionality on the effectiveness of Midazolam administered preoperatively to children. Anesthesiology 2007; 107:545-52.

21. Jobeir A, Galal MO, Bulbul ZR, et al. Use of low-dose Ketamine and/or Midazolam for pediatric cardiac catheterization. Pediatric Cardiology 2003;24:236-43.

22. Berman W, Fripp R, Rubler $M$ et al: Hemodynamic effects of ketamine in children undergoing cardiac catheterization. Pediatr Cardiol 1990, 11(2):72-76.

23. Wathen JE, Roback MG, Mackenzie T, et al. Does midazolam alter the clinical effects of intravenous ketamine sedation in children? A double-blind, randomized, controlled, emergency department trial. Ann Emerg Med 2000;36:579-88.

24. Williams GD, Philip BM, Chu LF, et al. Ketamine does not increase pulmonary vascular resistance in children with pulmonary hypertension undergoing sevoflurane anesthesia and spontaneous ventilation. Anesth Analg 2007;105:1578-84, table of contents.

25. Martin LD, Pasternak LR, Pudimat MA. total intravenous anesthesia with propofol in pediatric patients outside the operating room. Anesth Analg 1992;74:609-12.

26. Hertzog JH, Campbell JK, Dalton HJ, et al. Propofol anesthesia for invasive procedures in ambulatory and hospitalized children: experience in the pediatric intensive care unit. Pediatrics 1999;103:E30.

27. Ewen A, Archer DP, Samanani N, et al. Hyperalgesia during sedation: effects of barbiturates and propofol in the rat. Can J Anesth 1995; 42:532-40.

28. Sherry KM, Sartain J, Bell JH, et al. Comparison of the use of a propofol infusion in cardiac surgical patients with normal and low cardiac output states. J Cardiothorac Vasc Anesth 1995;9:368-72.

29. Bray RJ. Propofol infusion syndrome in children. Paediatr Anaesth 1998;8:491-9.

30. Cravens GT, Packer DL, Johnson ME. Incidence of propofol infusion syndrome during noninvasive radiofrequency ablation for atrial flutter or fibrillation. Anesthesiology 2007;106:1134-8.

31. Haase R, Sauer H, Eichler G. Lactic acidosis following short-term propofol infusion may be an early warning of propofol infusion syndrome. J Neurosurg Anesthesiol 2005;17:122-3.

32. Öklü E, Bulutcu FS, YalçIn Y, et al. Which anesthetic agent alters the hemodynamic status during pediatric catheterization? comparison of propofol versus ketamine. J Cardiothorac Vasc Anesth 2003;17:686-90.

33. Williams GD, Jones TK, Hanson KA, et al. The hemodynamic effects of propofol in children with congenital heart disease. Anesth Analg 1999;89:1411-6.

34. Gayatri P, Suneel PR, Sinha PK. Evaluation of Propofol-Ketamine anesthesia for children undergoing cardiac catheterization procedures. J Interv Cardiol 2007;20:15863 .

35. Kogan A, Efrat R, Katz J, et al. Propofol-ketamine mixture for anesthesia in pediatric patients undergoing cardiac catheterization. J Cardiothorac Vasc Anesth 2003;17: 691-3.

36. Akin A, Esmaoglu A, Guler G, et al. Propofol and Propofol-Ketamine in pediatric patients undergoing cardiac catheterization. Pediatr Cardiol 2005;26:553-7.

37. Munro HM, Tirotta CF, Felix DE, et al. Initial experience with dexmedetomidine for diagnostic and interventional cardiac catheterization in children. Paediatr Anaesth 2007;17:109-12.

38. Tosun Z, Akin A, Guler G, et al.Dexmedetomidine-Ketamine and Propofol-Ketamine combinations for anesthesia in spontaneously breathing pediatric patients undergoing cardiac catheterization. J Cardiothorac Vasc Anesth 2006;20:515-9.

39. Sarkar M, Laussen PC, Zurakowski D, et al. Hemodynamic responses to etomidate on induction of anesthesia in pediatric patients. Anesth Analg 2005;101:645-50.

40. Young C, Jevtovic-Todorovic V, Qin YQ, et al. Potential of ketamine and midazolam, individually or in combination, to induce apoptotic neurodegeneration in the infant mouse brain. Br J Pharmacol 2005;146: 189-97.

41. Fredriksson A, Ponten E, Gordh T, Eriksson P. Neonatal exposure to a combination of N-Methyl-d-aspartate and [gamma]Aminobutyric acid type A receptor anesthetic agents potentiates apoptotic neurodegeneration and persistent behavioral deficits. Anesthesiology 2007;107:427-36. 